\title{
The First Conserved Mitochondrial Genome of Polygraphus Poligraphus (Coleoptera: Curculionidae) and Its Phylogenetic Implications
}

\author{
Xianmei Song \\ Ningxia University \\ Yuchen Zhao \\ Ningxia University \\ Peng Zhao \\ Ningxia University \\ Yinxiang Ma \\ Ningxia University \\ Ming Bai \\ Ningxia University \\ Xinpu Wang ( $\nabla$ wangxinpu@nxu.edu.cn ) \\ Ningxia University
}

\section{Research Article}

Keywords: bark beetle, mitogenome, phylogenetic analysis

Posted Date: September 23rd, 2021

DOI: https://doi.org/10.21203/rs.3.rs-923616/v1

License: () (1) This work is licensed under a Creative Commons Attribution 4.0 International License. Read Full License 


\section{Abstract}

Background: Polygraphus poligraphus L., the four-eyed spruce bark beetle, belongs to the Curculionidae (Coleoptera), which mainly harms Picea asperata Mast and Pinus armandii Franch tree trunks. So far, there is no mitochondrial genome reported for $P$. poligraphus.

Results: In this study, we sequenced and annotated the nearly complete mitogenome of $P$. poligraphus for the first time and predicted the secondary structures of its tRNAs. The results showed that the mitogenome of $P$. poligraphus was 15,302 bp (partial genome) in length with A + T content of $69.65 \%$ due to large-scale duplication. The nearly complete mitochondrial genome of $P$. Poligraphus contained a set of 36 genes typical of the insect mitogenome, including 13 protein-coding genes (PCGs), 2 ribosomal RNA genes (rRNAs), 21 transfer RNA genes (tRNAs) but lacked tRNA-lle, as for the typical insect mitogenome. The results of nucleotide skew statistics showed that the AT-skews and GC-skew of $P$. poligraphus were positive and negative, respectively, which were similar to other Scolytinae insects. All PCGs were initiated with the standard start codon ATN. All tRNA genes had the typical cloverleaf structure, except for the trnS1, which lacked a dihydroxyuridine (DHU) arm. Furthermore, we reconstructed phylogenetic trees of $P$. poligraphus based on the data set of the mitogenome's protein-coding gene sequences using the Bayesian inference (BI) method. Phylogenetic analysis indicated that the $P$. poligraphus mitogenome clustered with Gnathotrichus materiarius and Pityophthorus pubescens mitogenomes in a monophyletic manner. The phylogeny of these three genera of Scolytinae is presented as Polygraphus + (Gnathotrichus + Pityophthorus).

Conclusions: The results presented herein will provide a reference for further molecular taxonomy, evolution and phylogenetic research of $P$. poligraphus. However, additional mitogenome samples are still needed to more satisfactorily resolve the phylogeny of the Scolytinae.

\section{Background}

The mitochondrion is a fundamental eukaryotic organelle, descended from an alphaproteobacterium that formed a permanent symbiosis with the ancestral eukaryote roughly 2 billion years ago [1]. The mitochondrial genomes of arthropods have been studied extensively, and insects represent approximately $80 \%$ of the arthropod $\mathrm{mt}$ genomes that have been sequenced [1]. Insect mitochondrial genomes are small, typically a double-stranded circular molecular structure ranging from 14 to $19 \mathrm{~kb}$ in size. With few exceptions, all animal mitochondrial genomes contain a typical set of 37 genes: 13 protein-coding genes (PCGs) (ATP6, ATP8, COI-III, ND1-6, ND4L, and CYTB), 2 ribosomal RNA genes (rRNAs) (rnl and rns), 22 transfer RNA genes (tRNAs), and a putative control region (A + T-rich region) [2-4]. Compared with partial mitochondrial genes the whole mitogenome can provide more meaningful information such as the arrangement of gene sequences, secondary structures of RNA, codon usage and structural features of the $A+T$-rich region [5-7]. This is because of the unique features of a complete mitochondrial genome including simple genetic structure, maternal inheritance, high rate of evolution and low rate of 
recombination [8-10]. Over the past decade, mitochondrial genomes have become widely used for molecular evolution, population genetics, systematics and phylogenetics [1, 11-15].

Coleoptera, the largest insect order, contains 4 suborders (Archostemata, Adephaga, Polyphaga and Myxophaga), 17 superfamilies, 168 families and over 380,000 described species. Of these, about 10,000 are known in China $[16,17]$. Polygraphus poligraphus L., four-eyed spruce bark beetle, belongs to Scolytinae of Curculionidae of Coleoptera [18]. It is a harmful, wide-spread invasive insect and one of the 236 dangerous forest pests announced by the State Forestry and Grassland Administration of China. Polygraphus poligraphus is mainly distributed in Russia, Finland, Norway, Sweden, Denmark, Turkey, Poland, Czech Republic, Germany, Austria, former Yugoslavia and Gansu, Jilin, Liaoning, Heilongjiang, Neimenggu, and Ningxia provinces in China [19]. It mainly damages Picea asperata Mast and Pinus armandii Franch as adults and can cause the death of entire forests in severe cases. Nevertheless, $P$. asperata and $P$. armandii are important timber forests, ecological public welfare forests, water conservation forests and greening trees, and occupy an irreplaceable position in the forest resources of China $[19,20]$. The morphology, biology and biological and chemical control of $P$. poligraphus have been studied [21-23]. However, it is imperative to integrate the sustainable development of forest ecosystems with sustainable control techniques for bark beetles.

With the rapid development of high-throughput sequencing technology, the number of insect mitochondrial genomes being studied is increasing. Over two years there were more than 100 whole sequenced mitochondrial genomes and more than 1000 partially sequenced mitogenomes placed in the GenBank database for Coleoptera (last visited on March 25, 2021) [24]. Among these species, no information about the complete or nearly complete mitochondrial genome and phylogenetic position of $P$. poligraphus is mentioned, which impedes the application of biological control. In view of the large number of species of Scolytinae and the difficulty distinguishing them, accurate identification of these species is essential to prevent the invasion of these species. Here we report for the first time the nearly complete mitogenome of $P$. poligraphus and clarify its phylogenetic position within the Scolytinae.

In the present study we analyzed the genome organization, nucleotide composition, composition biases, codon usage, construct of tRNA secondary structures and phylogenetic relationships of the $P$. poligraphus mitogenome.

\section{Materials}

\section{Sample collection, identification and DNA extraction}

Adult specimens of the P. poligraphus were collected at Luoshan $\left(37^{\circ} 20^{\prime} 59^{\prime \prime} \mathrm{N}, 106^{\circ} 18^{\prime} 9^{\prime \prime} \mathrm{E}\right), 2108 \mathrm{~m}$, Ningxia, China on 15 Jun 2019. Currently the specimens are stored in the insect herbarium at the School of Agriculture, Ningxia University, China (SANXU, voucher number: YSSYXD201907). Fresh specimens were stored at $-80^{\circ} \mathrm{C}$ in $100 \%$ ethanol until used for DNA extraction. The specimens were identified by Dr. You Li (School of Forest Resources and Conservation, University of Florida, Gainesville, Florida 32611, 
USA). Total genomic DNA was extracted from the using NEBNext ${ }^{\circledR}$ Ultra ${ }^{\text {TM }}$ DNA Library Prep Kit according to the manufacturer's instructions.

\section{Mitogenome sequencing}

Illumina sequencing was used to obtain the mitogenome sequence of $P$. poligraphus. Briefly, qualified DNA samples tested by electrophoresis were randomly interrupted with Covaris ultrasonic crusher with a length of about $350 \mathrm{bp}$. Then, the whole library was constructed using the NEBNext ${ }^{\circledR}$ Ultra ${ }^{\mathrm{TM}}$ DNA Library Prep Kit for Illumina (NEB, USA) to repair the end of the DNA fragments, add poly'A', add sequencing joints, purify, PCR amplification and other steps. Subsequently, Qubit v2.0 was used for preliminary quantification, and the library was diluted to $2 \mathrm{ng} / \mu \mathrm{L}$. Lastly, Agilent 2100 was used to detect the inserted fragments of the library, the insert size was in line with the expectation, and the Q-PCR method was used to accurately quantify the effective concentration of the library to ensure the quality of the library.

\section{Mitogenome annotation and analysis}

The paired-end reads for mitochondrial genome sequences of $P$. poligraphus were assembled by MITObim v1.9 with the invertebrate genetic code employed [25]. Subsequently, the mitochondrial genomes of $P$. poligraphus were annotated with Geneious 10.1 .3 ((http://www.geneious.com/) with the mitogenomes of Pityogenes bidentatus (GenBank accession number KX035211) as references. Twentyone tRNA gene annotations were re-identified and their secondary structures predicted by MITOS Web Server (http://mitos.bioinf.uni-leipzig.de/index.py) [26]. Strand asymmetry was calculated according to the formulas: AT-skew $=[A-T] /[A+T]$ and GC-skew $=[G-C] /[G+C][27]$. The A + T content, AT-skew, GCskew, were graphically plotted by OriginPro 9.1 [28]. The base composition and the relative synonymous codon usage (RSCU) were calculated using MEGA version 7.0 [29].

\section{Phylogenetic analyses}

To reconstruct phylogenetic trees for the estimation of $P$. poligraphus taxonomic status, the complete mitogenome sequences of 19 Scolytinae species and three outgroups (Sitophilus zeamais, Cyrtotrachelus buqueti and Rhynchophorus ferrugineus) were downloaded from GenBank (Table 1). Ahead of Bayesian inference analysis, the Bioedit version 7.2.5 [30] was used to reconfirm the gene boundaries and remove the ambiguous sites by aligning the P. poligraphus and previously reported Scolytinae 13 PCGs. The nucleotide substitution model was individually selected for each of two rRNAs and three codon positions of concatenated PCGs using jModelTest version 2.1.4 [31] using the Akaike Information Criterion (AIC) [32]. The best-fit nucleotide substitution models were selected as ' $G T R+G+l$ '. The phylogenetic tree was reconstructed using Bayesian 3.2.0 [33] based on 13 mitochondrial protein-coding genes. 
Table 1

List of species used to construct the phylogenetic tree

\begin{tabular}{|c|c|c|c|}
\hline Family & Subfamily & Species & Accession number \\
\hline \multirow[t]{22}{*}{ Curculionidae } & Scolytinae & Anisandrus dispar & KX035217 \\
\hline & & Xylosandrus crassiusculus & KX035196 \\
\hline & & X. germanus & KX035202 \\
\hline & & X. morigerus & KX035191 \\
\hline & & Xyleborus sp. & KX035179 \\
\hline & & Cyclorhipidion bodoanus & KX035219 \\
\hline & & Dryocoetes autographus & KX035207 \\
\hline & & D. villosus & KX035216 \\
\hline & & Pityogenes bidentatus & KX035211 \\
\hline & & Ips sexdentatus & KX035215 \\
\hline & & Orthotomicus laricis & KX035213 \\
\hline & & Gnathotrichus materiarius & KX035218 \\
\hline & & Pityophthorus pubescens & KX035209 \\
\hline & & Hypothenemus sp. & KX035224 \\
\hline & & Trypophloeus asperatus & KX035204 \\
\hline & & Trypodendron domesticum & KX035205 \\
\hline & & T. signatum & KX035214 \\
\hline & & Hylastes attenuatus & KX035212 \\
\hline & & H. brunneus & KX035208 \\
\hline & Dryophthorinae & Sitophilus zeamais & KX373614 \\
\hline & & Cyrtotrachelus buqueti & MG674390 \\
\hline & & Rhynchophorus ferrugineus & KT428893 \\
\hline
\end{tabular}

\section{Results And Discussion}

\section{Genome organization and base composition}

Among the 20 Scolytinae species, P. poligraphus (GenBank accession number MN528600) had the smallest mitochondrial genome of 15,302 bp (partial genome) due to large-scale duplication, while Orthotomicus laricis had the largest of 18,887 bp (Fig. 1). The nearly complete mitochondrial genome of 
P. poligraphus contained the set of 36 genes typical of insect mitogenomes: 13 protein-coding genes (PCGs) (ATP6, ATP8, COI-III, nad1-6, nad4L, and cob), 2 ribosomal RNA genes (rRNAs) (12S rRNA and 16S rRNA), 21 tRNAs (lack tRNA-lle). Twenty-two genes are encoded on the majority strand (L-strand), and the remaining 14 genes are located on the minority strand (H-strand) in this mitogenome (Table 2). 
Table 2

Mitochondrial genome organization of Polygraphus poligraphus

\begin{tabular}{|c|c|c|c|c|c|c|c|}
\hline Feature & Strand & Location & Size(bp) & $\begin{array}{l}\text { Start } \\
\text { code }\end{array}$ & $\begin{array}{l}\text { Stop } \\
\text { codon }\end{array}$ & Anticodon & $\begin{array}{l}\text { Intergenic } \\
\text { nucleotides }\end{array}$ \\
\hline $\operatorname{trnQ}$ & $\mathrm{H}$ & $346-413$ & 68 & & & TTG & -1 \\
\hline $\operatorname{trnM}$ & L & $413-481$ & 69 & & & CAT & 0 \\
\hline nad2 & L & $482-1486$ & 1,005 & ATT & TAA & & 2 \\
\hline $\operatorname{trnW}$ & L & $1489-1556$ & 68 & & & TCA & 0 \\
\hline $\operatorname{trnC}$ & $\mathrm{H}$ & $1557-1623$ & 67 & & & GCA & 4 \\
\hline $\operatorname{trn} Y$ & $\mathrm{H}$ & $1628-1692$ & 65 & & & GCA & 34 \\
\hline $\operatorname{cox} 1$ & L & $1727-3229$ & 1,503 & ATC & TAA & & 2 \\
\hline $\operatorname{trnL2}$ & L & $3232-3294$ & 63 & & & TAA & 0 \\
\hline $\operatorname{cox} 2$ & L & $3295-3973$ & 679 & ATT & $\mathrm{T}$ & & 0 \\
\hline trnK & L & $3974-4043$ & 70 & & & CTT & 0 \\
\hline $\operatorname{trnD}$ & L & $4044-4107$ & 64 & & & GTC & 0 \\
\hline atp8 & L & $4108-4266$ & 159 & ATT & TAG & & -7 \\
\hline atp6 & L & $4260-4934$ & 675 & ATG & TAA & & -1 \\
\hline $\operatorname{cox} 3$ & L & $4934-5719$ & 786 & ATG & TAA & & 6 \\
\hline $\operatorname{trnG}$ & L & $5726-5789$ & 64 & & & TCC & 0 \\
\hline nad3 & L & $5790-6143$ & 354 & ATA & TAA & & 8 \\
\hline $\operatorname{trn} A$ & L & $6152-6215$ & 64 & & & TGC & 0 \\
\hline $\operatorname{trnR}$ & L & $6216-6279$ & 64 & & & TCG & 1 \\
\hline $\operatorname{trnN}$ & L & $6281-6345$ & 65 & & & GTT & -1 \\
\hline trnS1 & L & $6345-6404$ & 60 & & & TCT & 1 \\
\hline trnE & L & $6406-6466$ & 61 & & & TTC & -1 \\
\hline $\operatorname{trnF}$ & $\mathrm{H}$ & $6466-6531$ & 66 & & & GAA & 0 \\
\hline nad5 & $\mathrm{H}$ & $6532-8227$ & 1,696 & ATT & $\mathrm{T}$ & & 0 \\
\hline $\operatorname{trnH}$ & $\mathrm{H}$ & $8228-8294$ & 67 & & & GTG & 0 \\
\hline nad4 & $\mathrm{H}$ & $8295-9622$ & 1,328 & ATG & TA & & -7 \\
\hline nad4l & $\mathrm{H}$ & $9616-9909$ & 294 & ATG & TAG & & 3 \\
\hline
\end{tabular}




\begin{tabular}{|c|c|c|c|c|c|c|c|}
\hline Feature & Strand & Location & Size(bp) & $\begin{array}{l}\text { Start } \\
\text { code }\end{array}$ & $\begin{array}{l}\text { Stop } \\
\text { codon }\end{array}$ & Anticodon & $\begin{array}{l}\text { Intergenic } \\
\text { nucleotides }\end{array}$ \\
\hline $\operatorname{trnT}$ & L & $9913-9977$ & 65 & & & TGT & 0 \\
\hline $\operatorname{trn} P$ & $\mathrm{H}$ & $\begin{array}{l}9978- \\
10041\end{array}$ & 64 & & & TGG & 2 \\
\hline nad6 & L & $\begin{array}{l}10044- \\
10550\end{array}$ & 507 & ATG & TAA & & 0 \\
\hline cob & L & $\begin{array}{l}10551- \\
11689\end{array}$ & 1,139 & ATG & TA & & 0 \\
\hline $\operatorname{trnS2}$ & L & $\begin{array}{l}11690- \\
11755\end{array}$ & 66 & & & TGA & 9 \\
\hline nad1 & $\mathrm{H}$ & $\begin{array}{l}11765- \\
12700\end{array}$ & 936 & ATT & TAA & & 19 \\
\hline $\operatorname{trnL} 1$ & $\mathrm{H}$ & $\begin{array}{l}12720- \\
12786\end{array}$ & 67 & & & TAG & -40 \\
\hline $\mathrm{rrnL}$ & $\mathrm{H}$ & $\begin{array}{l}12747- \\
14080\end{array}$ & 1,334 & & & & -12 \\
\hline $\operatorname{trnV}$ & $\mathrm{H}$ & $\begin{array}{l}14069- \\
14136\end{array}$ & 68 & & & TAC & -1 \\
\hline rrnS & $\mathrm{H}$ & $\begin{array}{l}14136- \\
14907\end{array}$ & 772 & & & & -- \\
\hline
\end{tabular}

The nucleotide composition of the P. poligraphus mitochondrial genome was $37.26 \%$ of A, $32.39 \%$ of T, $18.46 \%$ of $C, 11.89 \%$ of $G$ and $69.65 \%$ of $A+T$ content (Table 3 ). Generally, the whole mitogenomes of Scolytinae exhibited a strong base composition bias toward $66.15 \%$ (Gnathotrichus materiarius) $77.46 \%$ (Hylastes brunneus) for A + T content. The entire mitogenomes with a high A + T content benefit from the composition of PCGs, tRNAs and rRNAs. Scolytinae. The A + T content in tRNAs was higher than that in PCGs in all 20 species. Hylastes brunneus had relatively weaker tRNA A + T content compared with other Scolytinae species (Fig. 2A). In addition to the A + T content, the skewness (AT-skew and GC-skew) of the base composition in nucleotide sequences was also used to describe the base composition of mitogenomes [27, 34]. The results of nucleotide skew statistics show that the AT-skews of $P$. poligraphus were slightly positive. The AT-skews of PCGs, tRNAs and rRNAs for whole mitogenomes in the Scolytinae are positive because the AT-skews value of nad1, nad4, nad4L, nad5 and $\mathrm{rnn} L$ are relatively greater and in other regions are slightly negative. Compared with other species, the AT-skews of $G$. materiarius were slightly less lower (Fig. 2B). The GC-skew values are all negative in whole mitogenomes. The GC-skew of P. poligraphus is similar to other Scolytinae insects (Fig. 2C). The nucleotide skewness in Scolytinae mitochondrial genomes is consistent with that of most other insects [34]. 
Table 3

Composition and skewness in the Polygraphus poligraphus mitogenome.

\begin{tabular}{|lllllllll|}
\hline Region & Size(bp) & A\% & G\% & C\% & T\% & A+T\% & AT-Skew & GC-Skew \\
\hline Mitogenome & 15,302 & 37.26 & 11.89 & 18.46 & 32.39 & 69.65 & 0.070 & -0.216 \\
\hline PCGs & 11061 & 37.36 & 11.97 & 19.06 & 31.62 & 68.98 & 0.083 & -0.228 \\
\hline tRNAs & 1375 & 38.11 & 11.20 & 16.65 & 34.04 & 72.15 & 0.056 & -0.196 \\
\hline rRNAs & 2106 & 39.08 & 8.02 & 17.09 & 35.80 & 74.88 & 0.044 & -0.361 \\
\hline
\end{tabular}

\section{Protein-coding genes and codon usage}

The PCGs of the mitogenome were 11,061 bp long for P. poligraphus (Table 3). Four PCGs (nad1, nad4, nad4L and nad5) were encoded on H-strand, and the other nine PCGs were located the L-strand. The sizes of 13 PCGs ranged from $159 \mathrm{bp}$ (atp8) to $1696 \mathrm{bp}$ (nad5) in P. poligraphus (Table 2). All 20 mitogenomes had similar characteristics with the smallest sized PCG of atp8 and the largest that of nad5. All PCGs in the $P$. poligraphus mitogenomes started with the standard ATN codon. The start codon ATG was shared with cox3, atp6, nad4, nad4L, nad6 and cob; the start codon ATT was shared with cox2, atp8, nad1, nad2 and nad5; cox1 started with codon ATC; and the nad3 started with codon ATA. The conservative stop codon TAA was shared with cox1, cox3, atp6, nad1, nad2, nad3 and nad6; the stop codon TAG was shared with atp8 and nad4L; nad4 and cob stop with an incomplete codon "TA-", and cox2 and nad5 end with the single nucleotide "T-". "TA-" and "T-"' denote that the TAA stop codon is presumed to be completed by the addition of $3^{\prime}$ " $A$ " residues to the mRNA. The incomplete termination codons are common across arthropod mitogenomes and are completed by post-transcriptional polyadenylation during the mRNA maturation process $[35,36]$.

The amino acid composition and the relative synonymous codon usage (RSCU) of mitogenomes of $P$. poligraphus and the other 19 Scolytinae species are summarized in Fig. 3 . The total number of codons in the PCGs ranged from 3060 (Hylastes attenuatus) to 3836 (Dryocoetes villosus). The pattern of codon usage was generally similar among Scolytinae mitogenomes such as the seven most frequently used codons: UUU, UUA, UAU, AUU, AAA, AAU and AUA, all composed wholly of A or U. In the P. poligraphus mitogenome, 3,542 amino acids were translated, of which 1,196 (33.77\%) were encoded by the seven frequently used codons above. And, in the $H$. brunneus mitogenome, 1,672 (45.55\%) amino acids were encoded by the seven frequently used codons; this was the greatest in the 20 Scolytinae mitogenomes. However, the codons absent in Scolytinae mitogenomes were different. In the Xylosandrus crassiusculus, P. pubescens and Ips sexdentatus mitogenomes, the GCG codon was absent, whereas the CCG and CGU codons were absent in Trypodendron domesticum and Dryocoetes autographus respectively. In general, the high $\mathrm{C} / \mathrm{G}$ content in the absent codons effectively reflects nucleotide $\mathrm{A}+\mathrm{T}$ bias in the mitochondrial PCGs among Scolytinae.

\section{Transfer and ribosomal RNA genes}


The 21 tRNAs of the $P$. poligraphus mitogenomes were scattered discontinuously over the partial mitogenome (due to large-scale duplication). The length of 21 tRNA genes ranged from $60 \mathrm{bp}$ (trnS1) to $70 \mathrm{bp}$ (trnK). The total length of tRNAs was $1,375 \mathrm{bp}$, accounting for approximately $9 \%$ of the mitogenome. Among them, eight tRNA genes were transcribed from the $\mathrm{H}$-strand and 13 from the Lstrand (Table 2). As shown in Fig. 4, most tRNAs sequences could fold into the typical clover-leaf secondary structure (including amino acid acceptor (AA) arm, dihydrouridine (DHU) arm, variable (V) loop, anticodon (AC) arm and TWC (T) arm), while trnS1 (AGN) forms a simple loop due to lacking the stable DHU arm. The lack of a DHU stem in trnS1 is generally present in Coleoptera insects and has been confirmed as a typical feature of metazoan mitogenomes [1, 24 37-41]. In tRNA genes of the $P$. poligraphus mitogenome, a great number of nucleotide substitutions are found in five different stems. Compared with variable T $\Psi$ C and DHU loops, the anticodon stem and loop is highly conserved (Fig. 4). Except for the classic AU and CG pairs, we recognized 21 mismatched base pairs in the tRNA genes secondary structures of $P$. poligraphus. Among them, 19 were G-U mismatched base pairs, one was a U-U pair and two were G-G pairs. The overrepresented pattern of the non-canonical G-U pairs in tRNA genes of the mitogenome is commonly present in other insects [24, 42].

Two rRNA genes (rrnL and rrnS) were transcribed from the $\mathrm{H}$-strand in P. poligraphus. The larger rrnL was 1,334 bp long, and located between the trnL1 and trnV, while the smaller rrnS was 772 bp in length and located behind trnV (Fig. 1, Table 2). The rRNA genes presented a heavy AT nucleotide bias, with A+T content $74.88 \%$ in P. poligraphus (Table 3). In the 20 mitogenomes of Scolytinae analyzed, the lengths of $\mathrm{rrnL}$ ranged from 1,239 (Trypophloeus asperatus) to 1,372 (O. laricis) bp, and of rrnS from 755 ( $G$. materiarius) to 815 (P. bidentatus) bp.

\section{Overlapping sequences and intergenic spacers}

The mitogenome of $P$. Poligraphus have a total of $74 \mathrm{bp}$ overlap sequences and $91 \mathrm{bp}$ intergenic spacer sequences, which are all made up of 12 regions in the range from 1 to $40 \mathrm{bp}$ and 1 to $34 \mathrm{bp}$ respectively. The longest overlap region is located between trnL1 and $\mathrm{rnL}$, and the longest intergenic spacer region is located between trnY and cox1. However, in other Scolytinae species, the longest overlap region is located between tRNA-Leu1and $\mathrm{rrnL}$ up to $66 \mathrm{bp}$ (G. materiarius), and the longest intergenic spacer region is located between rrnS and tRNA-lle up to $2,061 \mathrm{bp}$ (P. bidentatus). All 19 Scolytinae species (except $O$. laricis) have indentical overlap regions, atp8-atp6 (7 bp); and all 16 Scolytinae species (except $T$. asperatus, D. autographus, Pityophthorus pubescens and P. bidentatus) also have indentical overlap regions, atp6-cox3 (1 bp). In 20 Scolytinae species, other regions (except tRNA-Asp-atp8 and tRNA-ThrtRNA-Pho regions) more and less present overlap or intergenic spacer sequences.

\section{Phylogenetic analysis}

We reconstructed phylogenetic trees based on the 20 Scolytinae species and three outgroups (S. zeamais, C. buqueti and R. ferrugineus) 13 mitogenomes PCGs using Bayesian 3.2.0 (Fig. 5). Phylogenetic analysis showed that the $P$. poligraphus mitogenome clustered clearly with the $G$. 
materiarius and $P$. pubescens mitogenomes in a monophyletic manner. The phylogeny of these three genera of Scolytinae is presented as Polygraphus + (Gnathotrichus + Pityophthorus). The result is consistent with previous results based on traditional classification analyses. The principal aim of this study was to determine the phylogeny of Scolytinae and the location of $P$. poligraphus. On the one hand, since we did not sample all the genera of the Scolytinae, a more comprehensive sampling of the taxa is needed to fully resolve the genus relationships within the Scolytinae. On the other hand, our study adds to the limited data in existing databases. Most of the phylogenys of Scolytinae are reconstructed based on mitogenomes $[43,44]$, and we believe that more nuclear genes are needed to clarify the genus relationship of Scolytinae.

\section{Conclusions}

In this present study, we sequenced and annotated the nearly complete mitogenome of $P$. poligraphus and predicted the secondary structures of its tRNAs. The results showed that our newly-determined mitogenome of $P$. poligraphus had a similar composition to the typical insect mitogenome. In the secondary structure of tRNA, the lack of a DHU stem in trnS1 is consistent with all Coleoptera insects and has been confirmed as a typical feature of metazoan mitogenomes. Our $P$. poligraphus mitogenome provides an important data resource for further studies and contributes to our understanding of the phylogeny. However, additional mitogenome samples are still needed to more satisfactorily resolve the phylogeny of the Scolytinae.

\section{Declarations}

\section{Acknowledgements}

We are grateful to Dr. You Li (School of Forest Resources and Conservation, University of Florida, Gainesville, Florida 32611, USA) for identifying specimens.

\section{Funding}

This research was supported by the Key Research and Development Project of Ningxia (2021BEG02009), the First-class discipline of Prataculture Science of Ningxia University (No. NXYLXK2017A01) and the National Natural Science Foundation of China (No. 31961143002).

\section{Ethics approval and consent to participate}

All experimental procedures were approved by the School of Agriculture of Ningxia University.

\section{Consent for publication}

Not applicable.

\section{Competing interests}


The authors declare that they have no competing interests.

\section{Availability of supporting data}

Mitochondrial genome sequence can be accessed via accession number MN528600 in GenBank of NCBI at https://www.ncbi.nlm.nih.gov/. The associated BioProject, SRA, and BioSample numbers are PRJNA713518, SRR13972118 and SAMN18253525, respectively.

\section{Authors' contributions}

XM S assembled, finished, and annotated mitochondrial and plastid genomes and all data analyses, submitted sequences to NCBI, and wrote the first draft of all sections of the manuscript.YC Z and P Z assisted in collecting Polygraphus poligraphus. YX M participated in the experiments. M B and XP W supervised this study, contributed to the design of the study and drafting the manuscript. All authors read and approved the final manuscript.

\section{References}

1. Cameron SL. Insect mitochondrial genomics: implications for evolution and phylogeny. Annu. Rev. Entomol. 2014; 59: 95-117. https://doi.org/10.1146/annurev-ento-011613-162007.

2. Wolstenholme DR. Animal mitochondrial DNA: structure and evolution. Int. Rev. Cytol. 1992; 141: 173-216. https://doi.org/10.1016/S0074-7696(08)62066-5.

3. Boore JL. Animal mitochondrial genomes. Nucleic Acids Res. 1999; 27: 1767-1780. https://doi.org/10.1093/nar/27.8.1767.

4. Li H, Gao JY, Liu HY, Cai WZ. Progress in the researches on insect mitochondrial genome and analysis of gene order. Science Foundation in China. 2009; 17: 39-47. https://doi.org/10.1088/10050841/17/2/004.

5. Song N, Liu HY, Yang XJ, Zhao XC, Lin AL. Complete mitochondrial genome of the darkling beetle Gonocephalum outreyi (Coleoptera: Tenebrionidae) with phylogenetic implications. J. Asia-Pac Entomol. 2018; 21: 721-730. https://doi.org/10.1016/j.aspen.2018.05.001.

6. Hu P, Wang R. The complete mitochondrial genome of Parantica sita sita (Lepidoptera: Nymphalidae: Danainae) revealing substantial genetic divergence from its sibling subspecies P. s. niphonica. Gene. 2019; 686: 76-84. https://doi.org/10.1016/j.gene.2018.10.088.

7. Wang Y, Cao JJ, Li N, Ma GY, Li WH. The first mitochondrial genome from Scopuridae (Insecta: Plecoptera) reveals structural features and phylogenetic implications. Int. J. Biol. Macromol. 2019; 122: 893-902. https://doi.org/10.1016/j.ijbiomac.2018.11.019.

8. Curole JP, Kocher TD. Mitogenomics: digging deeper with complete mitochondrial genomes. Trends Ecol. Evol. 1999; 14: 394-398. https://doi.org/10.1016/S0169-5347(99)01660-2.

9. Lin CP, Danforth BN. How do insect nuclear and mitochondrial gene substitution patterns differ? Insights from Bayesian analyses of combined datasets. Mol. Phylogenet. Evol. 2004; 30: 686-702. 
https://doi.org/10.1016/S1055-7903(03)00241-0.

10. Ho SYW, Gilbert MTP. Ancient mitogenomics. Mitochondrion. 2010; 10: 1-11. https://doi.org/10.1016/j.mito.2009.09.005.

11. Ribera I, Nilsson AN, Vogler AP. Phylogeny and historical biogeography of Agabinae diving beetles (Coleoptera) inferred from mitochondrial DNA sequences. Mol. Phylogenet. Evol. 2004; 30: 545-562. https://doi.org/10.1016/S1055-7903(03)00224-0.

12. Zhang ZQ, Wang XJ, Li RZ, Guo RJ, Zhang W, Song W, Hao CF, Wang HP, Li ML. The mitochondrial genome of Dastarcus helophoroides (Coleoptera: Bothrideridae) and related phylogenetic analyses. Gene. 2015; 560: 1-9. https://doi.org/10.1016/j.gene.2014.12.026.

13. Zhang HL, Liu N, Han ZP, Liu JX. Phylogenetic analyses and evolutionary timescale of Coleoptera based on mitochondrial sequence. Biochem. Syst. Ecol. 2016; 66: 229-238. https://doi.org/10.1016/j.bse.2016.04.014.

14. Sun HQ, Zhao WX, Lin RZ, Zhou ZF, Huai WX, Yao YX. The conserved mitochondrial genome of the jewel beetle (Coleoptera: Buprestidae) and its phylogenetic implications for the suborder Polyphaga. Genomics. 2020; 112: 3713-3721. https://doi.org/10.1016/j.ygeno.2020.04.026.

15. Zeng LY, Pang YT, Feng SQ, Wang YN, Stejskal V, Aulicky R, Zhang SF, Li, ZH. Comparative mitochondrial genomics of five Dermestid beetles (Coleoptera: Dermestidae) and its implications for phylogeny. Genomics. 2021; 113: 927-934. https://doi.org/10.1016/j.ygeno.2020.10.026.

16. Hatch MH. The natural classification of the families of Coleoptera. Ann. Entomol. Soc. Am. 1956; 49; 102. https://doi.org/10.1093/aesa/49.1.102.

17. Hunt T, Bergsten J, Levkanicova Z, Papadopoulou A, John OS, Wild R, Hammond PM, Ahrens D, Balke M, Caterino MS, Gómez-Zurita J, Ribera I, Barraclough TG, Bocakova M, Bocak L, Vogler AP. A comprehensive phylogeny of beetles reveals the evolutionary origins of a superradiation. Science. 2007; 318: 1913-1916. https://doi.org/10.1126/science.1146954.

18. Wood SL. Introduced and exported American Scolytidae (Coleoptera). Great Basin Naturalist, 1977; 37: 67-74. https://www.jstor.org/stable/41711552.

19. Kang XM. Risk analysis of Polygraphus poligraphus, a dangerous pest. Forestry of Shanxi. 2016; 3 : 44-45. (in chinese) https://doi.org/10.3969/j.issn.1005-4707.2016.06.019.

20. Duan XJ. Polygraphus poligraphus special investigation and its potential hazards. Rural Science and Technology. 2020; 3: 34-36. https://doi.org/10.19777/j.cnki.issn1002-6193.2020.03.015.

21. Yin HF, Huang FS, Li ZL. Economic Entomology of China (Sect. 29: Coleoptera: Scolytidae). Beijing: Science Press. 1984; 56-183. ISBN: 13031-2621. (in chinese)

22. Sun XL. Studies on species and genera of Scolytidae (Insecta: Coleptera) with reference to invasive to China. Beijing Forestry University. (2005). (in chinese)

23. Viklund L, Rahmani R, Bång J, Schroeder M, Hedenström E. Optimizing the attractiveness of pheromone baits used for trapping the four-eyed spruce bark beetle Polygraphus poligraphus. J. Appl. Entomol. 2019; 143: 721-730. https://doi.org/10.1111/jen.12641. 
24. Jeong JS, Kim MJ, Kim I. The mitochondrial genome of the dung beetle, Copris tripartitus, with mitogenomic comparisons within Scarabaeidae (Coleoptera). Int. J. Biol. Macromol. 2020; 144: 874891. https://doi.org/10.1016/j.jjbiomac.2019.09.165.

25. Hahn C, Bachmann L, Chevreux B. Reconstructing mitochondrial genomes directly from genomic next-generation sequencing reads-a baiting and iterative mapping approach. Nucleic Acids Res. 2013; 41: e129. https://doi.org/10.1093/nar/gkt371.

26. Bernt M, Donath A, Jühling F, Externbrink F, Florentz C, Fritzsch G, Pütz J, Middendorf M, Stadler PF. MITOS: improved de novo metazoan mitochondrial genome annotation. Mol. Phylogenet. Evol. 2013; 69: 313-319. https://doi.org/10.1016/j.ympev.2012.08.023.

27. Perna NT, Kocher TD. Patterns of nucleotide composition at fourfold degenerate sites of animal mitochondrial genomes. J. Mol. Evol. 1995; 41: 353-358. https://doi.org/10.1007/BF01215182.

28. Seifert E. OriginPro 9.1: Scientific Data Analysis and Graphing Software-Software Review. J. Chem. Inf. Model. 2014; 54: 1552. https://doi.org/10.1021/ci500161d.

29. Kumar S, Stecher G, Tamura K. MEGA7: Molecular Evolutionary Genetics Analysis Version 7.0 for Bigger Datasets, Mol. Biol. Evol. 2016; 33: 1870-1874. https://doi.org/10.1093/molbev/msw054.

30. Hall TA. BioEdit: a user-friendly biological sequence alignment editor and analysis program for Windows 95/98/NT. Nucleic Acids Symp. 1999; 41: 95-98. https://doi.org/10.1021/bk-19990734.ch008.

31. Darriba D, Taboada GL, Doallo R, Posada D. jModelTest 2: more models, new heuristics and parallel computing. Nat. Methods. 2012; 9: 772. https://doi.org/10.1038/nmeth.2109.

32. Akaike H. A new look at the statistical model identification. IEEE Trans. Autom. Control 1974; 19: 716-723. https://doi.org/10.1109/TAC.1974.1100705.

33. Ronquist F, Teslenko M, Van Der Mark P, Ayres DL, Darling A, Höhna S, Larget B, Liu L, Suchard MA, Huelsenbeck JP. MrBayes 3.2: efficient Bayesian phylogenetic inference and model choice across a large model space. Syst. Biol. 2012; 61: 539-542. https://doi.org/10.1093/sysbio/sys029.

34. Wei SJ, Shi M, Chen XX, Sharkey MJ, Achterberg C, Ye GY, He JH. New views on strand asymmetry in insect mitochondrial genomes. PLOS One. 2010; 5: e12708. https://doi.org/10.1371/journal.pone.0012708.

35. Ojala D, Montoya J, Attardi G. tRNA punctuation model of RNA processing in human mitochondria. Nature. 1981; 290: 470-474. https://doi.org/10.1038/290470a0.

36. Schuster G, Stern D. RNA polyadenylation and decay in mitochondria and chloroplasts. Prog. Mol. Biol. Transl. Sci. 2009; 85: 393-422. https://doi.org/10.1016/S0079-6603(08)00810-6.

37. Wang WQ, Huang YX, Bartlett CR, Zhou FM, Meng R, Qin DZ. Characterization of the complete mitochondrial genomes of two species of the genus Aphaena Guérin-Méneville (Hemiptera: Fulgoridae) and its phylogenetic implications. Int. J. Biol. Macromol. 2019; 141: 29-40. https://doi.org/10.1016/j.jijbiomac.2019.08.222.

38. Wolstenholme DR. Genetic novelties inmitochondrial genomes of multicellular animals. Curr. Opin. Genet. Dev. 1992; 2: 918-925. https://doi.org/10.1016/S0959-437X(05)80116-9. 
39. Garey JR, Wolstenholme DR. Platyhelminth itochondrial DNA: evidence forearly evolutionary origin of a tRNA ${ }^{\text {ser }} A G N$ that contains a dihydrouridine arm replacement loop, and of serine-specifying AGA and AGG codons. J. Mol. Evol. 1989; 28: 374-387. https://doi.org/10.1007/BF02603072.

40. Chen ZT, Du YZ. The first two mitochondrial genomes from Taeniopterygidae (Insecta: Plecoptera): structural features and phylogenetic implications. Int. J. Biol. Macromol. 2017; 111: 70-76. https://doi.org/10.1016/j.jibiomac.2017.12.150.

41. Lavrov DV, Brown WM, Boore JL. A novel type of RNA editing occurs in the mitochondrial tRNAs of the centipede Lithobius forficatus. PNAS. 2000; 97: 13738-13742. https://doi.org/10.1073/pnas.250402997.

42. W.Z. Yang, Y. Zhang, S.Q. Feng, L.J. Liu, Z.H. Li, The first complete mitochondrial genome of the Japanese beetle Popillia japonica (Coleoptera: Scarabaeidae) and its phylogenetic implications for the superfamily Scarabaeoidea. Int. J. Biol. Macromol. 118 (2018) 1406-1413. https://doi.org/10.1016/j.jibiomac.2018.06.131.

43. Stauffer C, Lakatos F, Hewitt GM. The phylogenetic relationshipsof seven European Ips (Scolytidae, Ipinae) species. Insect Molecular Biology. 1997; 6: 233-240. https://doi.org/10.1046/j.13652583.1997.00177.x.

44. Cognato Al, Sperling FAH. Phylogeny of Ips DeGeer species (Coleoptera: Scolytidae) inferred from mitochondrial cytochrome oxidase I DNA sequence. Mol. Phylogenet. Evol. 2000; 14: 445-460. https://doi.org/10.1006/mpev.1999.0705.

\section{Figures}




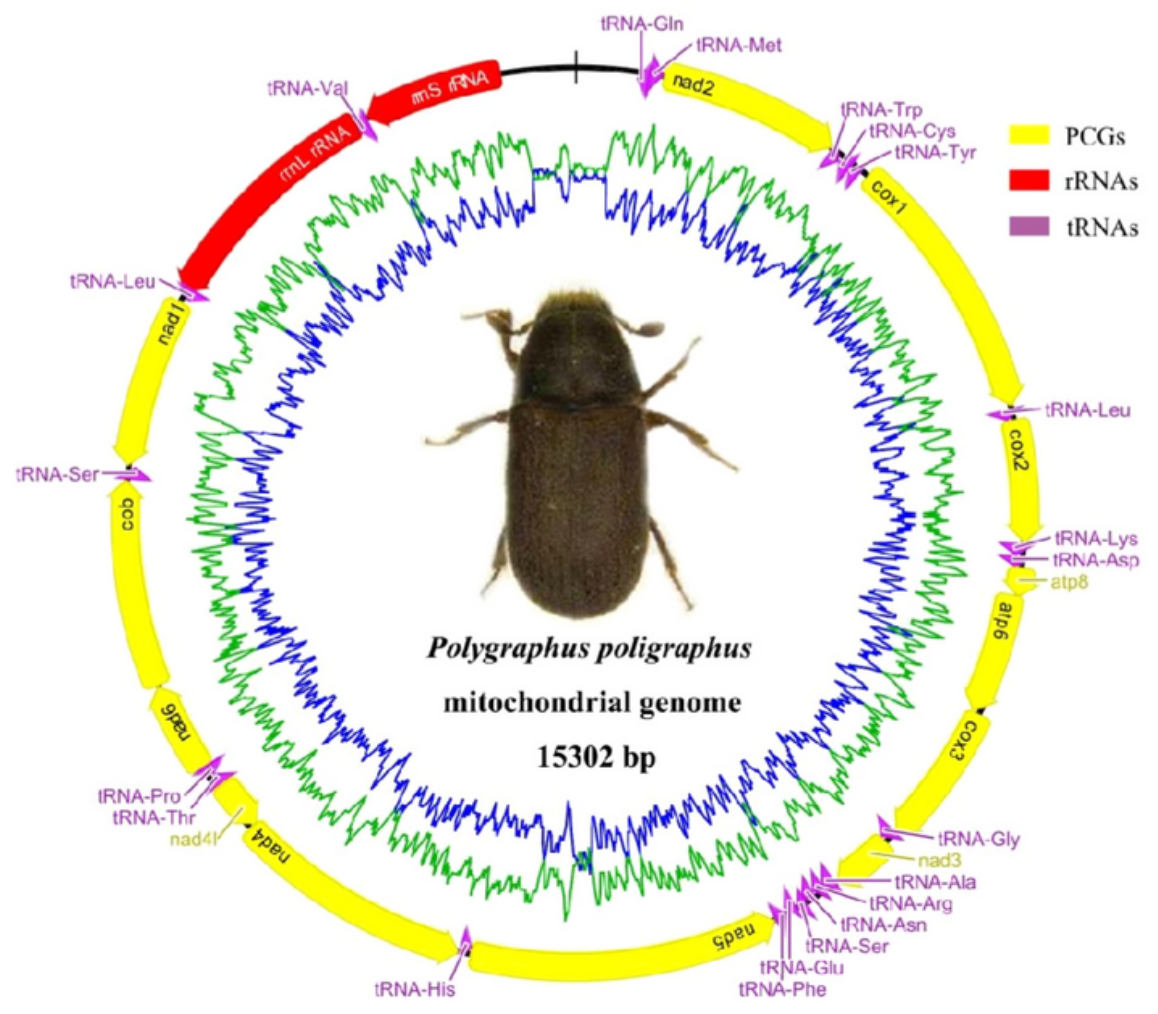

\section{Figure 1}

Mitochondrial genome map of the Polygraphus poligraphus. Circular map was drawn with Geneious 10.1.3 (http://www.geneious.com/). The transcriptional direction is indicated with arrows. 

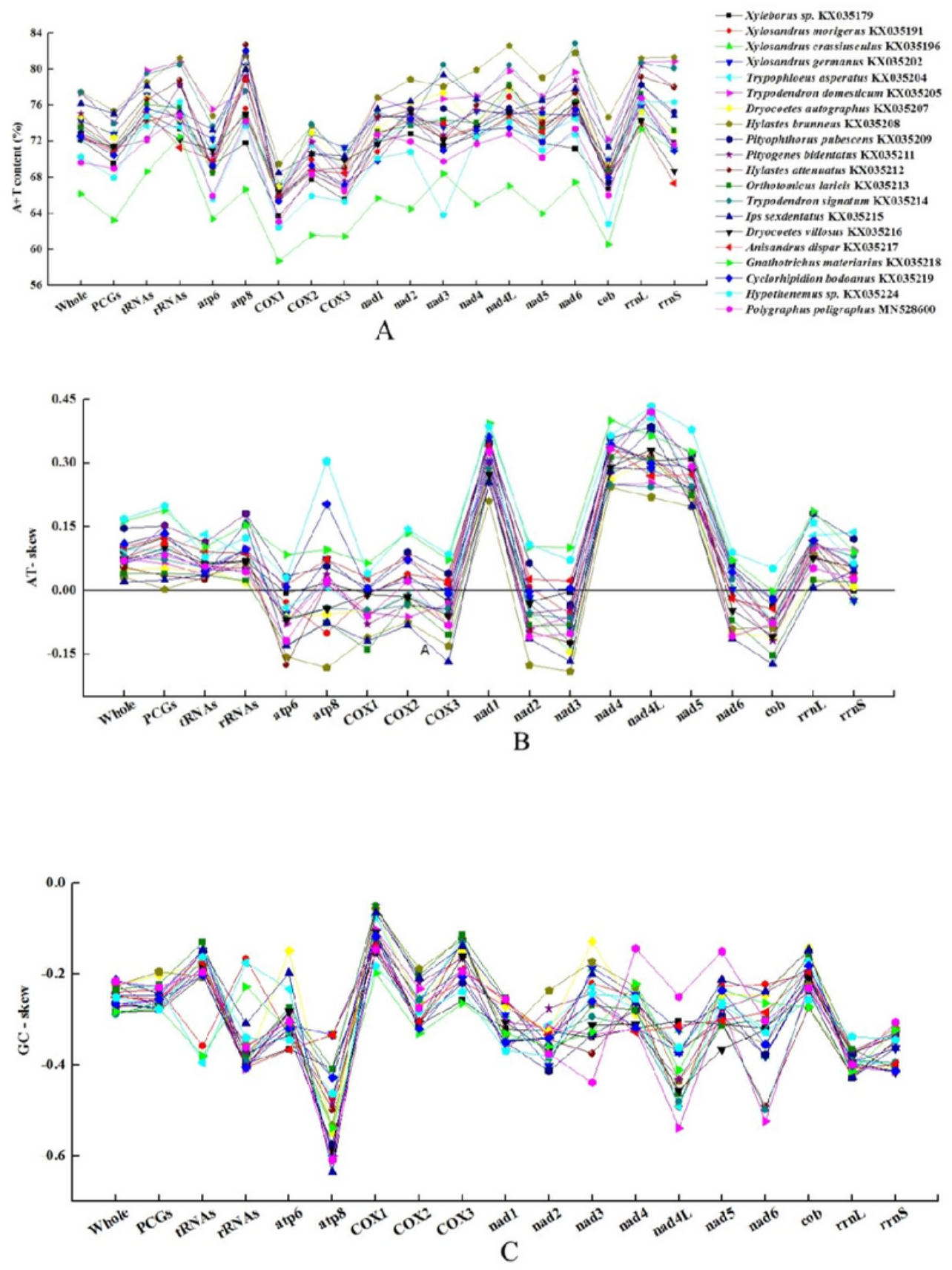

Figure 2

Comparison of the A + T contents, nucleotide skewness of twenty speciesof Scolytinae. (A) A + T content; (B) AT-skew; (C) GC-skew. 

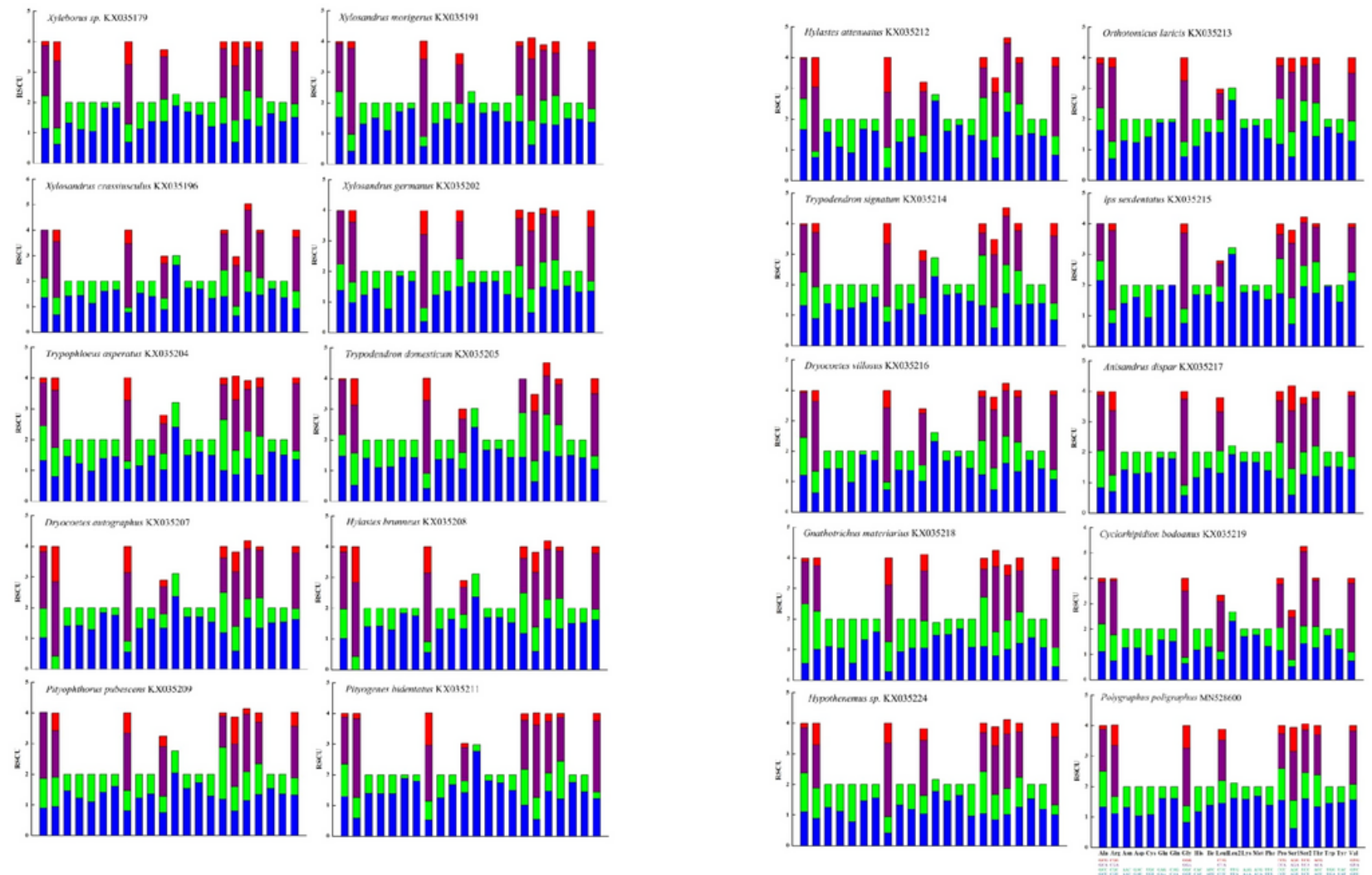

Figure 3

Relative synonymous codon usage (RSCU) of the mitogenomes of twenty species of Scolytinaw 

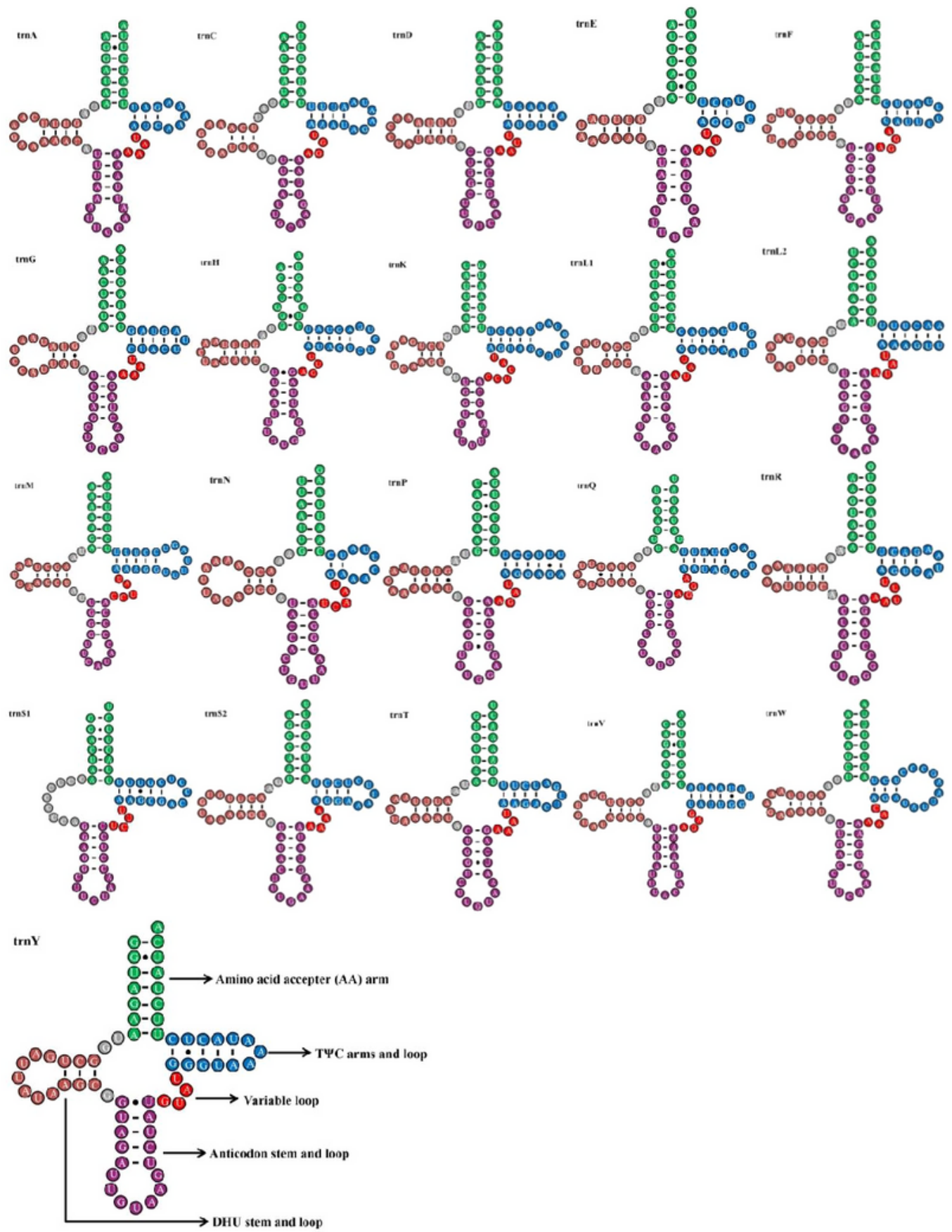

Figure 4

Secondary structure for the tRNAs of Polygraphus poligraphus 


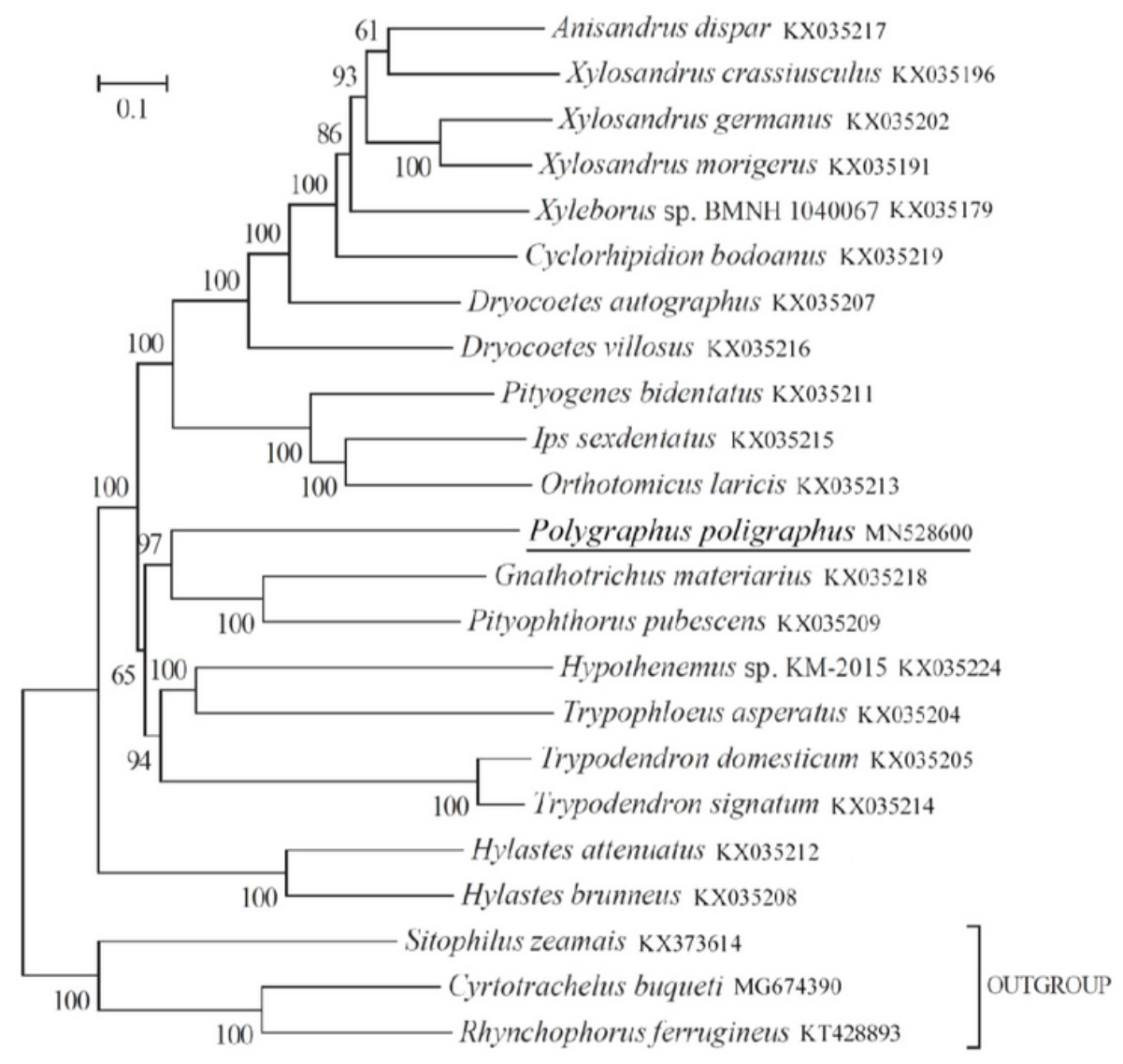

Figure 5

Phylogeny of 20 species within the Scolytinae based on the Bayesian analysis of 13 mitochondrial protein-coding genes. 'GTR+G+l' was used as the best-fit nucleotide substitution model. The support values are shown next to the nodes. Three species within the subfamily Dryophthorinae were included as the outgroup taxa. 